\title{
Closure planning in a developing country-a case study from the Phu Kham Mine, Laos, Southeast Asia
}

\author{
A.P. Mauric Golder Associates Pty Ltd, Australia \\ C.D. McCullough Golder Associates Pty Ltd, Australia \\ C. Wilson-Clark Golder Associates Pty Ltd, Australia
}

A. Witcomb Phu Bia Mining Limited, Laos

J. Millgate Phu Bia Mining Limited, Laos

\begin{abstract}
Mining in developing regions face significant challenges for effective closure planning. A regulatory environment that has not reached maturity in the area of mine closure and limited capacity within government to regulate mine closure issues can present considerable risk from an operation to the regional community and environment. Alternatively, if the operation adopts leading practice international standards in recognition of their corporate responsibilities and social license-to-mine in developing countries, there may be significant opportunities for enhanced social and environmental outcomes for the host country and mining company.

Using a case study from the Phu Kham Mine, Lao People's Democratic Republic (Laos), we discuss some of the key challenges to closure planning, including the limitations of closure regulation and community capacity to assimilate closure issues, in a developing country. We describe how leading mine closure planning can be achieved in a developing country using leading practice international standards. The practical application of these standards is already leading to significant social outcomes in the areas of community development through initiatives targeting health, education and economic opportunities. When planning for closure, the focus must shift towards a longer term view, which endeavours to use the remaining years of the operation to prepare local communities for post-mining independence and sustainable benefits. We highlight the potential for both social and environmental benefits post-closure and the degree of planning required to get there.
\end{abstract}

\section{$1 \quad$ Introduction}

\section{$1.1 \quad$ Mine closure}

Mining is not a new phenomenon and it is well established that poor planning and management may lead to environmental impacts (Lottermoser, 2007). Mines may be closed due to depletion of economically mineable resources, low mineral prices (Cochilco, 2002; ICMM, 2008) and inability to achieve economic and operational targets due to legal and political changes (Laurence, 2002). Mine closure planning helps manage and mitigate the social and environmental risks arising from this process. Integrated mine closure is also important for mining companies in ensuring their business sustainability, their social licence-tooperate as well as reducing the financial, environmental and legal risks. Simple abandonment of a mine without proper closure has historically led to a legacy of poor mining practices in both developed and developing nations (Clark, 1999; Dhindsa et al., 2003; Harrison et al., 2003; Johnson, 2003; Navarro et al., 2008). The intention of mine closure planning is to enable a mining company to close operations with minimum liability and risk remaining to company and stakeholders such as national and local governments, communities and the environment surrounding the mine (Figure 1). Leading practice closure planning achieves this mitigation of risk through early and continuous engagement with stakeholders to direct a 
clear and well-documented closure strategy that informs all parts of the life of mine with the key aims of economic, social and environmental sustainability (Jones, 1996). Closure planning is a continuous process which should extend throughout the life of a mine, from the exploration phase through to closure, post closure and site relinquishment (ICMM, 2008) (Figure 2). Nevertheless, although closure planning begins at a conceptual phase and develops toward a more definitive strategy and plan, a clear understanding of closure aims, objectives and regulatory requirements are necessary throughout the process. Having a clear understanding of the wider opportunities surrounding the mine, whether physical, ecological or socioeconomic is another often over-looked aspect of integrated mine closure.

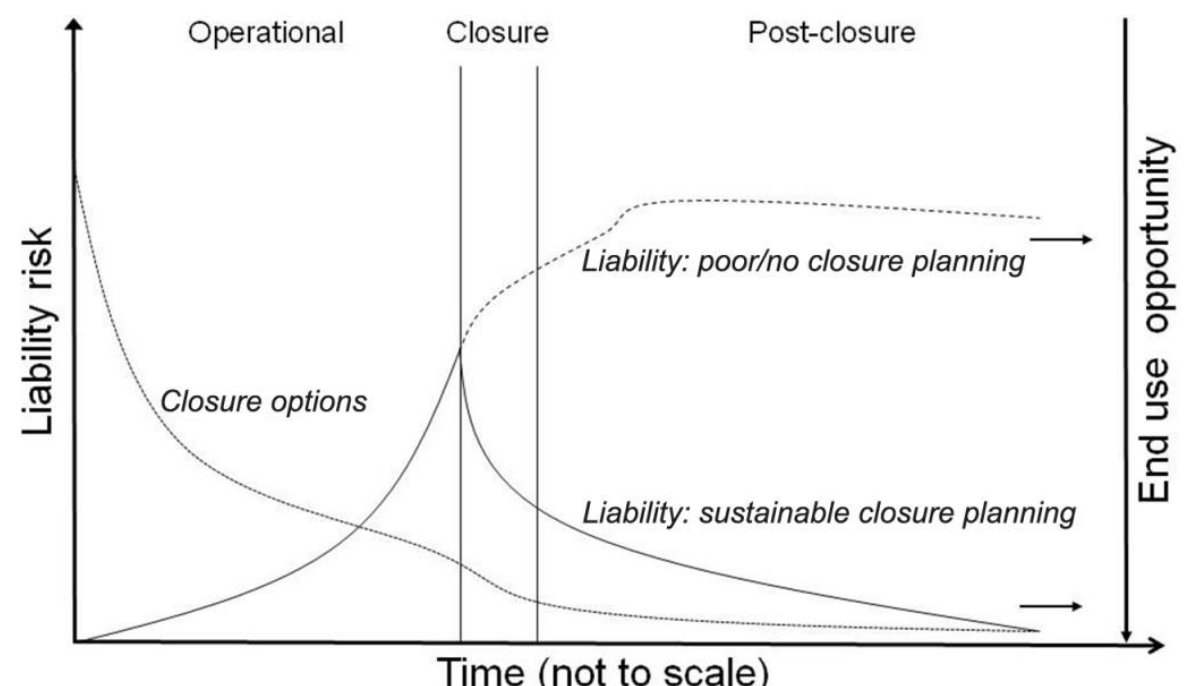

Figure 1 The intention of mine closure is to remove, or reduce, risks remaining following closure of the mining operation

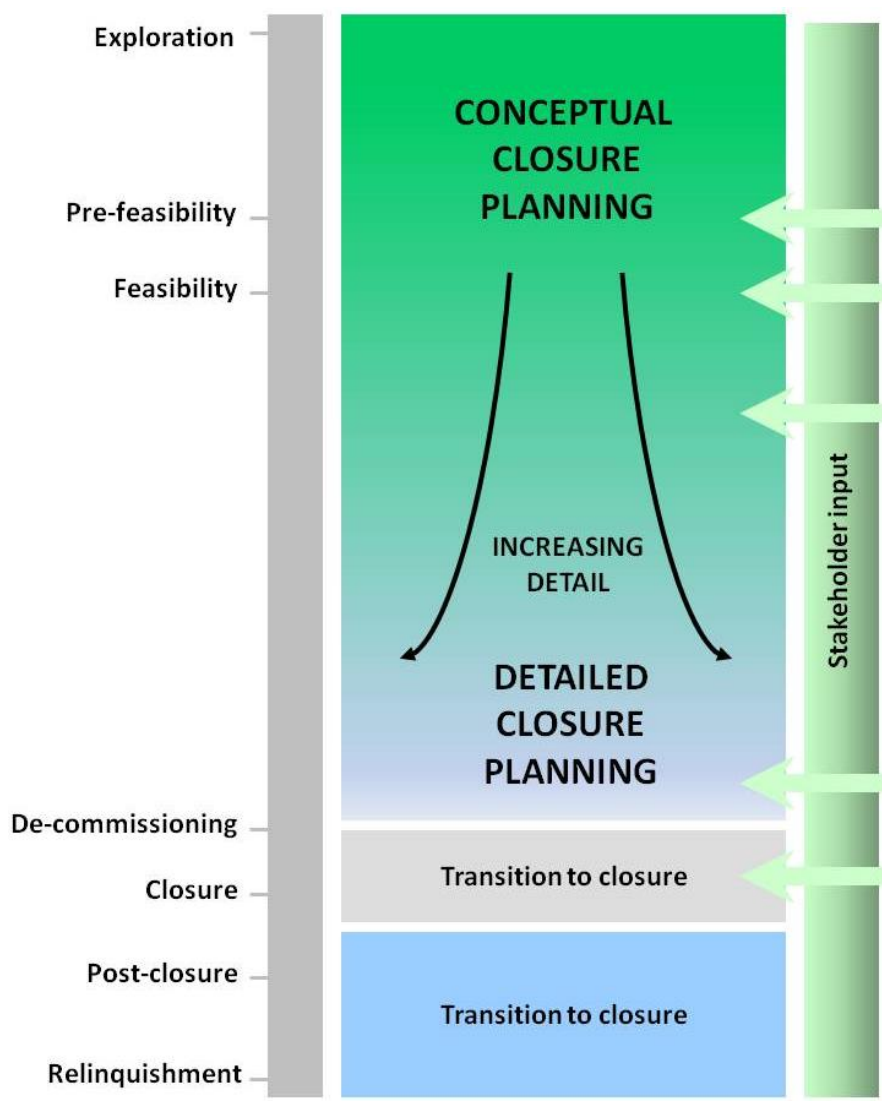

Figure 2 Mine closure planning should be a continuous process involving with stakeholder input throughout (ICMM, 2008) 


\subsection{Mining in developing countries}

Mineral resources development in developing countries is increasingly important for regional employment, economic growth, and infrastructure development. However, regulation of mining, particularly in developing nations, is often not enforced, or for economic reasons may be overruled, leaving potential for social and environmental impacts following closure (Lottermoser, 2007).

Land use practices often found around southeast Asian mine sites, such as slash and burn agriculture and artisanal mining adjacent to or upstream of an operation, may conflict with rehabilitation and closure planning criteria. Finucane et al. (2011) summarised some of the key issues constraining mine reclamation and closure in Indonesia as:

- The formulative nature of the regulatory framework for mine closure.

- Difficulties in setting achievable success or closure criteria, including lack of spatial plans for almost all regions.

- The capacity and priority of local, regional and national governments to manage implementation of the mine closure regulation prior to, during and following mine closure.

- Sustaining communities post-closure and avoiding dependence.

- The impacts of artisanal miners and illegal loggers on a closed mine site.

- Managing stakeholders' expectations, etc.

Like other developing regions, south-east Asia has a poor recent mining environmental record. The remoteness of many mining operations and the high rate of development in many of the region's countries contributed to this record (Wälde, 1992). Environmental impacts have not always been related to the scale of mining. Mine closure has typically been uncontrolled and ad hoc. A fundamental limitation for regulation of mining in developing countries may be the absence of clear guidance from host nation regulators on the environmental and social performance standard expected of them (Burke, 2006).

\subsection{International guidance}

In order to obtain environmental impact assessment approvals, most developed nation mining regulations require mine operators to develop and submit a mine closure plan (MCP) to at least a conceptual level of detail, at the planning stage of a new mine. These regulations emphasise the importance of a welldocumented and managed integrated MCP for the economic, social and environmental sustainability of a region (Bridge, 2004).

Multi-national companies that operate in more developed regions with higher degrees of (often) more prescriptive regulation (Jones, 2008), as well as developing nations, may have either standards or broad guidance applicable to all their operations in all host countries as a result, e.g. Rio Tinto (2009). However, for companies mainly based in the rapidly growing mining regions of Asia and Africa, this lack of local performance requirements means that mine closure planning is often not mandatory and may hence be less likely to occur.

Generic international guidance for the context of mine closure plans is available through organisations such as the International Finance Corporation (IFC, 2007) and the International Council on Mining and Metals (ICMM, 2008). Developed mining nations, like Australia, also have well developed mine closure planning guidelines for example, ANZMEC/MCA (2000) and DMP/EPA (2011).

Using a case study from the Phu Kham Mine, Laos, we demonstrate how general international guidance can provide direction for a leading standard of mine closure planning. We also demonstrate how specific closure objectives can be directed as 'proxy' regulation by mines operating in regions without more specific closure planning regulations. 


\section{2}

\section{Case study}

\section{$2.1 \quad$ Operation}

Phu Bia Mining Limited (PBM) has operating assets and associated commitments in the developing Asian region in Laos and Thailand. Pan Australian Resources Limited (PanAust) currently owns a 90\% interest in PBM through the company's wholly owned subsidiary Pan Mekong Exploration Pty Limited, with the Government of Laos owning $10 \%$. PanAust is an international emerging gold and copper producer listed on the Australian Stock Exchange.

PBM has a Mineral Exploration and Production Agreement (MEPA) with the Government of Laos to develop gold and copper resources in the Xaisomboun District of the Vientiane Province. The Phu Kham CopperGold Project ('Phu Kham') is the second phase of PBM's development of assets in Laos.

Mining operations commenced at Phu Kham in 2008 with an estimated mine life of 14 years. The Phu Kham project involves open cut mining and processing of the sulphide copper-gold resource underlying the Phu Kham Gold Cap. Ore is processed using conventional flotation techniques to produce a copper-gold concentrate and no cyanide is used. The current life-of-mine plan for Phu Kham will see production ending in early 2023, and closure planning is currently at a conceptual stage.

\subsection{Site location}

Phu Kham is located in the Northern Highlands area of Laos, in the Xaisomboun District of Vientiane Province, approximately $110 \mathrm{~km}$ north-northeast of Vientiane, the capital of Laos (Figure 3).

Laos is a subtropical to tropical country with two principal seasons. The wet season is from May to October, during the southwest monsoon. The remainder of the year is generally dry. Precipitation varies from about $1,200 \mathrm{~mm}$ per year in the lowlands to over $3,000 \mathrm{~mm}$ in the mountainous areas, which exceeds evaporation (around $1,000 \mathrm{~mm}$ per year). Average temperatures range between $15^{\circ} \mathrm{C}$ to $35^{\circ} \mathrm{C}$, with the coolest period between December and January, and the hottest months around March to April.

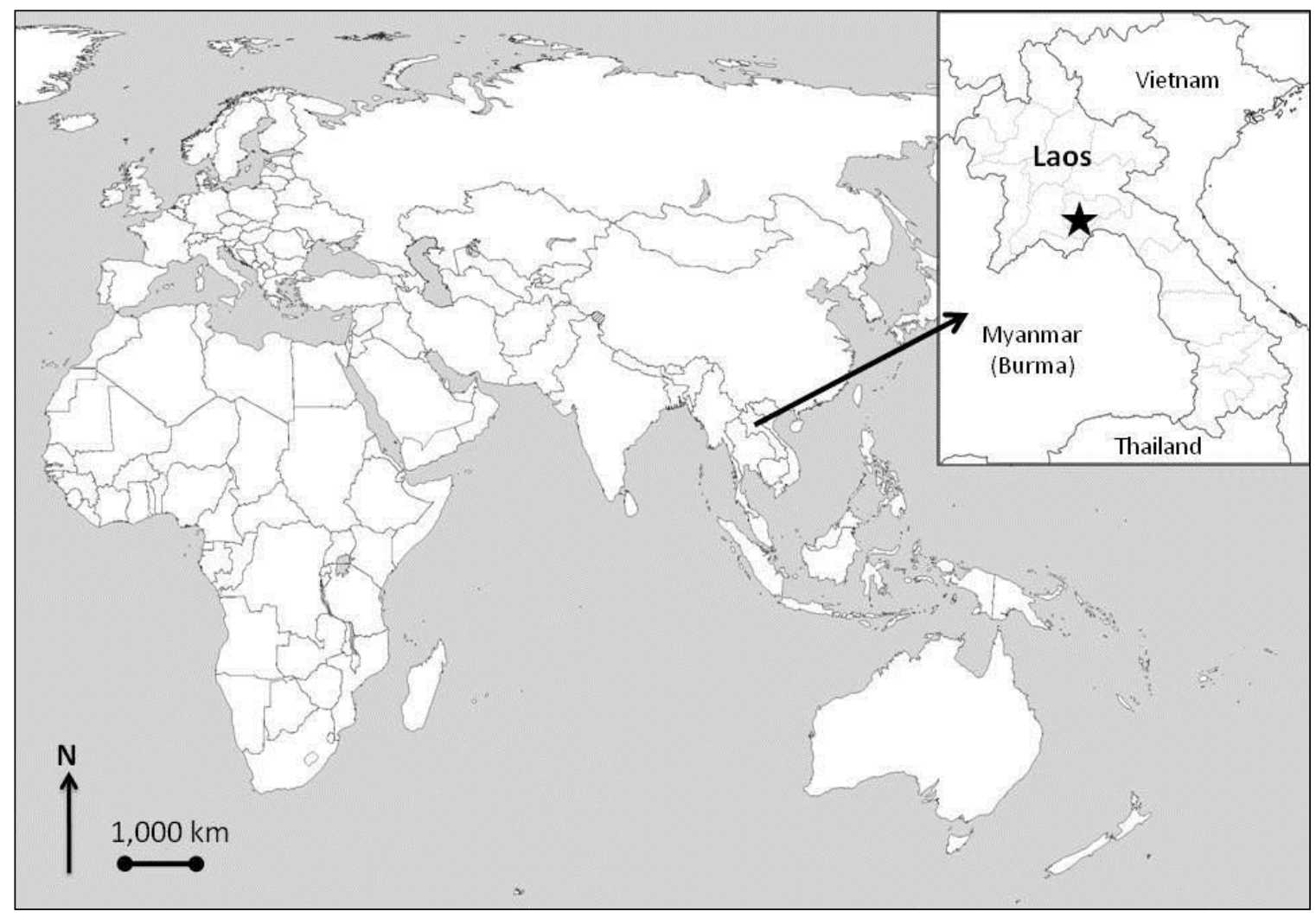

Figure 3 Location of the Phu Kham Mine 
The Phu Kham deposit is located in hilly terrain characterised by sharp ridgelines and steep sided valleys, with elevations between 700 and 1,200 m above sea level (masl) (Figure 4a). Phu Kham project infrastructure lies within the Nam Mo River catchment, which is a tributary of the Nam Ngum River. The Nam Mo River joins the Nam Ngum River approximately $14 \mathrm{~km}$ southwest of the Phu Kham deposit. The Nam Ngum reservoir is approximately $40 \mathrm{~km}$ downstream of the project area.
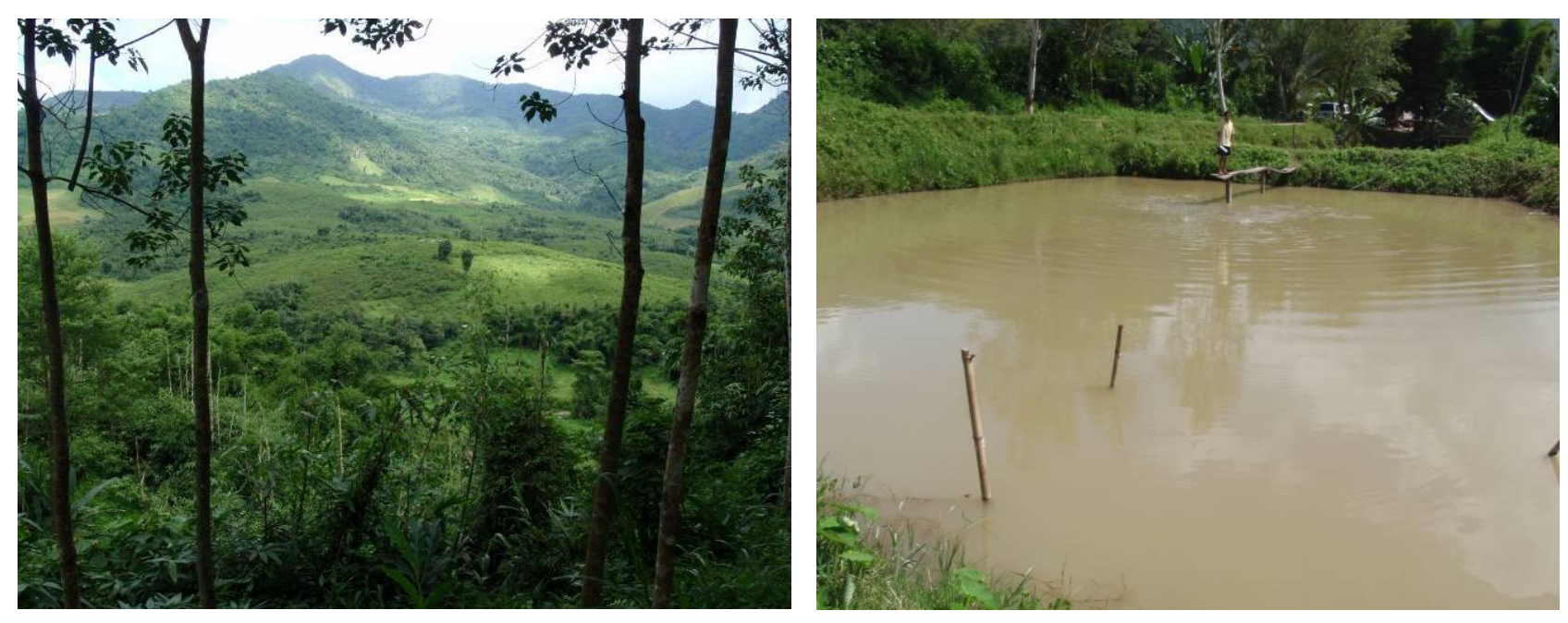

Figure 4 Left to right: a) landscape around the Phu Kham Mine, b) community development aquaculture initiatives

\subsection{Social setting}

Xaisomboun Province is traditionally one of the poorest and least densely populated areas of Laos. Prior to the commencement of PBM operations, the region had minimal industrial activity and was primarily based on a subsistence economy. Agricultural land is limited to lowland rice paddy cultivation and upland rice agriculture and the Nam Ngum catchment and its tributaries provide food sources for nearby villages. There is a mixed ethnic population in the two villages nearest the mine; Ban Nam Gnone and Ban Nam Mo. Villager's ethnic origins include Khmu, Hmong, Tai Deng, Tai Dam and Ethnic Lowland Lao.

Demographically, Laos is a young country, with about half of the population under the age of 20. Recently, PBM has funded the construction of a number of additional schools in villages close to the Phu Kham operation through the medium of its Community Development Fund. Almost all villages now have primary level education and some lower secondary level education, however, the adult population of the region has received little or no formal education. Adult education is now provided through PBM Community Development programs.

The standard of village living is low with only basic housing, water supply and sanitation facilities in most villages. Houses in the Phu Kham area are generally bamboo or semipermanent. Sanitation facilities are improving due to a continuous awareness programme on health and hygiene and investment by PBM.

PBM conducted extensive data collection for social and economic information relating to the communities impacted by the Phu Kham operations. This included baseline surveys in 2003 and 2005 for the purposes of the Environmental and Social Impact Assessment (ESIA) and follow-up socio-economic surveys conducted in 2007, 2008 and 2010. The most recent data shows continuing migration into the village nearest to the mine, Ban Nam Gnone. This shift is primarily due to the increased opportunities closer to the PBM operations relative to the time prior to the mine's arrival.

PBM's Community Development Fund provides significant support to local social investment programmes, with a current annual spending commitment of US\$300,000. The projects are identified in consultation with local and district authorities and are subject to approval by provincial authorities. A perpetual fund has not yet been considered. Current community development objectives are geared toward promoting local 
ownership of initiatives, addressing root causes of socio-economic disadvantage and ensuring benefits are shared fairly and equally. Existing programs target assistance in the areas of agriculture, aquaculture, horticulture, local infrastructure, education, health, microfinance and small business development. Villagers have eagerly participated in a Village Savings and Credit Fund program which enables microfinancing opportunities for small business ventures, including livestock, fish farming and drinking water (Figure 4b).

Nevertheless, a fundamental issue for mine closure in all countries, but particularly developing nations, is that the mine may bring many economic and employment opportunities into a region where previously there were none. The challenge for closure planning is how these opportunities can be managed to provide ongoing community benefit following closure (Roldan and Purvance, 2011).

There has been some concern on the part of residents of villages near the Phu Kham operation that people are becoming too reliant on the mine for employment and assistance. However, a primary principle of PBM closure planning has been to develop local livelihood opportunities that last beyond mine closure. For example, a microfinance-funded bottled drinking water company in Ban Nam Mo wished to sell all of their products to the Phu Kham Mine. Rather than purchasing 100\% of the total supply available, increasing dependence of the water company on the mine, PBM contracted for only $50 \%$. The same recognition and management of dependency holds for livestock, aquaculture and other small business ventures funded by the scheme. The fund also provides for business development training to assist village businesses establish other markets outside of the region.

\subsection{Existing Phu Kham regulation}

Although there is no specific guidance on mine closure regulatory requirements currently available in Laos, there are mineral development regulations as well as general environmental and social regulatory frameworks already in place that have been used to provide the initial direction to closure planning.

\subsubsection{MEPA agreement}

The Mineral Exploration and Production Agreement (MEPA) between the Government of Laos and PBM specifies the requirement for a Mine Closure and Rehabilitation Plan to be developed. However, the MEPA does not describe the structure, contents, level of detail or any specific local requirements required in the closure plan, nor does it specify a timeframe for completion or implementation.

There is a provision in the MEPA for the establishment of an environmental protection fund to be funded by PBM at the rate of US\$1/ounce of gold and US\$1/t of copper sold. The purpose of the fund is to undertake rehabilitation in accordance with the Phu Kham Environmental and Social Management and Monitoring Plan (ESMMP) (Figure 5). There is also a requirement for PBM to provide any additional funds required to complete agreed rehabilitation at completion and closure of the operation.

\subsubsection{Lao decree on environmental protection}

The Lao Decree on Environmental Protection (DEP) states that a plan must be developed to close the mine site and to restore the environment in mining areas, as well as budgeting for the implementation of the plan. In accordance with the Ministry of Natural Resources and Environment (MoNRE), prior to closing the mine site, a project developer must produce a plan on closure and restoration of the mining area. This plan must be submitted to MoNRE for consideration and approval prior to being implemented. A social development plan must also be finalised for the post-closure period and be approved prior to closure. However, similar to the MEPA agreement, there is no guidance on what detail or content the plans should contain or the timing for plan development.

\subsubsection{World Bank funding requirements (World Bank, 2010)}

PBM has not obtained funding by the World Bank for the Phu Kham operation. However, PBM voluntarily aims to comply with the International Finance Corporation (IFC) and Equator Principles. These require PBM 
to reserve funds sufficient to close its operation at any point and address the impacts associated with closure.
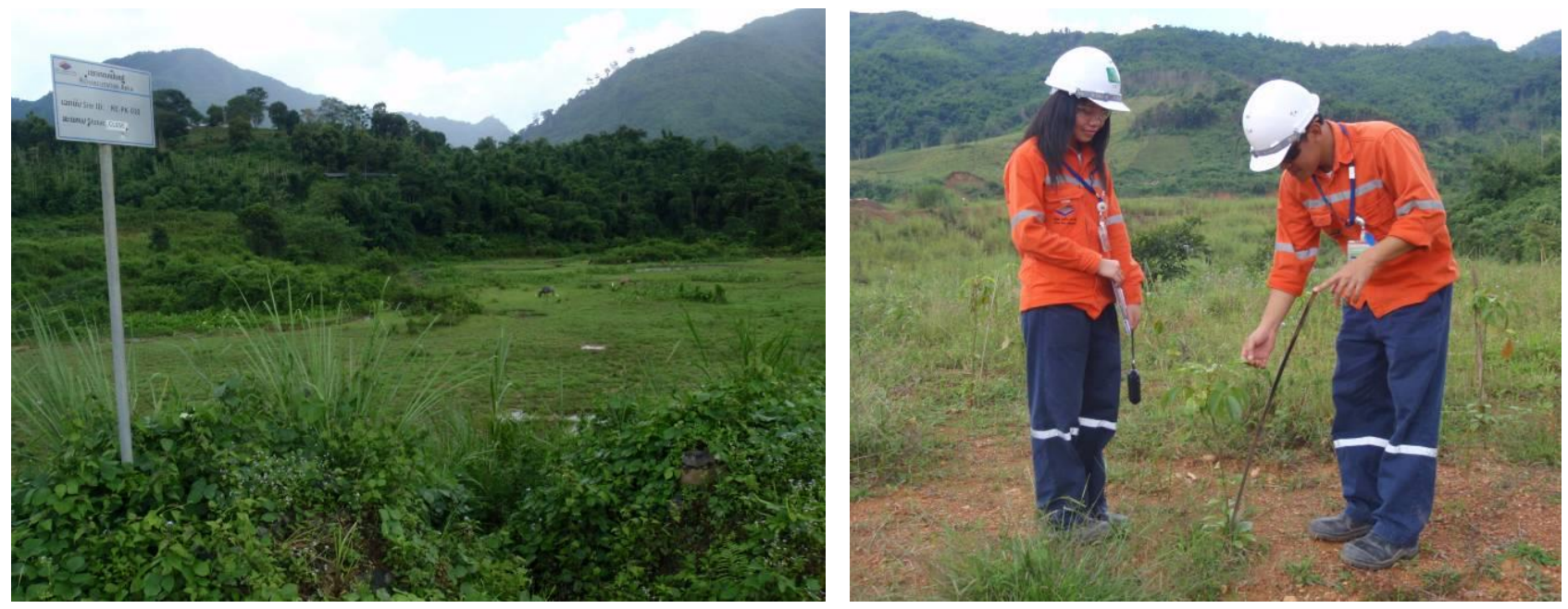

Figure 5 Left to right: a) rehabilitation staff inspecting seedling progress, b) completed rehabilitation of disturbed landform

\subsection{Applying international guidance as proxy regulation}

A conceptual MCP for Phu Kham was drafted in January 2009 upon commencement of the Phu Kham operation. This MCP was designed to be a guide for the closure of the Phu Kham site to satisfy requirements of licence and lease conditions, the expectations of community stakeholders, regulatory obligations, and standards set by PBM's Australia-based parent company PanAust.

In 2011, PBM identified the need to update its conceptual MCP to reflect current conditions and changes in life-of-mine plans, and to align it to a leading international environmental and social performance standard in closure planning. Key objectives were to understand closure risks better, identify further studies and planning that would be required during the remaining life-of-mine and allow development of an improved closure liability cost estimate.

PBM engaged Golder Associates Pty Ltd (Golder) (the consultants) to undertake a gap analysis of the Phu Kham operation's existing MCP and to benchmark it against leading international practice in closure planning. Further work involved scoping studies required to address any planning gaps identified. In the absence of detailed regulations to specify how the mine closure requirements of Lao PDR and the MEPA are to be implemented, the consultants recommended a number of international guidelines that could be used to synthesise a standard upon which future revision of the Phu Kham MCP could be based. This analysis, together with a site visit by consultant project staff and their and PBM staff's experience of leading practices at other mine sites, formed the basis to develop a revised MCP for Phu Kham.

The consultants identified international mine closure standards and guidelines that are relevant to the PBM operation, including:

- International Finance Corporation (IFC), Environmental, Health and Safety Guidelines for Mining (IFC, 2007).

- International Council on Mining and Metals (ICMM), Planning for Integrated Mine Closure: Toolkit (ICMM, 2008).

- IFC Environmental and Social Policy and Performance Standards (updated 2012).

- Minerals Council of Australia (MCA), Enduring Value (MCA, 2005).

- ANZMEC/MCA Strategic Framework for Mine Closure (ANZMEC/MCA, 2000). 
- Western Australian Department of Mines and Petroleum (DMP) and Environmental Protection Authority (EPA), Guidelines for Preparing Mine Closure Plans (DMP/EPA, 2011).

The overall finding of the Gap Analysis and Scoping Study was that PBM had, in most areas, adopted leading practice approaches to its management during operations. However, in order for this same social and environmental performance to be demonstrable following closure and gradual reduction and final cessation of PBM contributions to the region, what was now required was to reorientate these activities and directly link towards a closure planning perspective. For example, community development and social programs were operating effectively for the contemporary scenario, but there was little consideration given to engaging local stakeholders in the closure planning process.

Closure planning must also operate at a broader scale than just the immediate locale (Sklenička and Kašparová, 2008) and is often defined by catchment or regional approaches to planning (McCullough and Van Etten, 2011). Whilst Phu Kham closure planning was found to be good at a local scale, it was identified that there was a need to extend planning to incorporate the regional context and influences such as regional farming practices and potential post-closure land uses.

Studies were recommended to address these existing gaps and to strengthen PBM's mine closure planning and introduce systems for review which would provide a road map for future management teams. Apart from Stakeholder Engagement Planning, the team also identified additional water modelling for pit lake and tailings storage facility water balance and water quality, rehabilitation reviews, closure cost estimating and closure planning for human resources to fill remaining gaps in the identified leading practice standards. A risk assessment workshop incorporating employees, technical advisers and stakeholders of potential risks at closure and how these may be mitigated was also proposed.

Prior to revision of the MCP, the consultants also developed a Corporate Closure Standard (CCS) and MCP template to provide the principles and framework for life of mine closure planning at all PBM sites. As per the gap analysis and MCP review, the CCS and MCP template were, based upon the former review of international leading closure practice, PBM's current business approach and practices during operations and a review of other comparable company closure standards and strategies.

The new PBM CCS refers to international and Australian standards as well as PanAust and PBM policies and procedures and provides a working reference for management teams to provide a consistent structure and approach to closure planning. Golder Associates is now updating the MCP for the Phu Kham operation according to the targets and strategies developed as part of the corporate standard.

\section{Conclusions}

A lack of local regulations was not a significant hindrance to development of leading practice mine closure planning in this case study. This case study demonstrates how an existing sound approach to management of environmental and social issues during the operational phase of mining can be reorientated to a closure planning view. The identification and application of international mine closure guidelines and standards can provide a framework for advising existing mine closure planning and directing future planning, through a systematic understanding of knowledge gaps and closure risks.

General and narrative closure planning guidance documents are already available for mines operating in developing countries and regions. Detailed and more prescriptive planning guidance can also be sought from nations and regions where closure planning is more developed as long as it is always placed in context of the operating nation's economic environmental and social setting. For example, the ICMM and the IFC performance standards and guidelines can be supplemented with more detailed closure planning guidance from mining nations and states such as the Western Australian Government's guidance for mine closure planning.

PBM is now planning further studies through the remaining operational years to develop future revisions of the MCP documents that are progressively more detailed and informed at significantly higher levels. As decommissioning and closure approaches, closure planners will become increasingly equipped with 
sufficient project and contextual knowledge to further develop leading practice closure scenarios with the required higher levels of detail to achieve good closure outcomes for both company and stakeholders.

\section{References}

ANZMEC/MCA (2000) Strategic Framework for Mine Closure, by Australian and New Zealand Minerals and Energy Council/Minerals Council of Australia, Canberra, Australia, $27 \mathrm{p}$.

Bridge, G. (2004) Contested terrain: mining and the environment, Annual Review of Environment and Resources, Vol. 29, pp. 205-259.

Burke, G. (2006) Opportunities for environmental management in the mining sector in Asia, The Journal of Environment and Development, Vol. 15, pp. 224-235.

Clark, I. (1999) Planning for closure: The case of Australia, A. Warhurst and L. Noronha (eds), Environmental policy in mining: Corporate strategy and planning for closure, Boca Raton, USA, Lewis Publishers.

Cochilco (2002) Research on mine closure policy, by Cochilco, Chilean Copper Commission, Santiago, Chile, 94 p.

Dhindsa, H.S., Battle, A.R. and Prytz, S. (2003) Environmental emission of mercury during gold mining by amalgamation process and its impact on soils of Gympie, Australia, Pure and Applied Geophysics, Vol. 160, pp. 145-156.

DMP/EPA (2011) Guidelines for preparing mine closure plans, by Western Australian Department of Mines and Petroleum (DMP), Environmental Protection Authority of Western Australia (EPA), Perth, Australia, $78 \mathrm{p}$.

Finucane, S., Soeprapto, P., Wiryanto, K. and Ainscough, T. (2011) Challenges and opportunities for mine closure planning in Indonesia, in Proceedings Sixth International Conference on Mine Closure (Mine Closure 2011), A.B. Fourie, M. Tibbett and A. Beersing (eds), 19-21 September 2011, Lake Louise, Canada, Australian Centre for Geomechanics, Perth, Vol. 1, pp. 393-403.

Harrison, J., Heijnis, H. and Caprarelli, G. (2003) Historical pollution variability from abandoned mine sites, Greater Blue Mountains World Heritage Area, NSW, Australia, Environmental Geology, Vol. 43, pp. 680-687.

ICMM (2008) Planning for Integrated Mine Closure: Toolkit, by International Council on Mining and Metals London, UK, 86 p.

IFC (2007) Accessed, Environmental, Health and Safety Guidelines for Mining, May 2012, viewed http://www1.ifc.org/wps/ wcm/connect/1f4dc28048855af4879cd76a6515bb18/Final\%2B-\%2BMining.pdf?MOD=AJPERES\&id=1323153264157.

Johnson, D.B. (2003) Chemical and microbiological characteristics of mineral spoils and drainage waters at abandoned coal and metal mines, Water, Air, \& Soil Pollution: Focus, Vol. 3, pp. 47-66.

Jones, H. (1996) Minesite closure - a government perspective, AMPLA Yearbook, pp. 464-474.

Jones, H. (2008) Closure objectives, guidelines and actual outcomes, in Proceedings Third International Seminar on Mine Closure (Mine Closure 2008), A.B. Fourie, M. Tibbett, I.M. Weiersbye, P. Dye (eds), 14-17 October 2008, Johannesburg, South Africa, Australian Centre for Geomechanics, Perth, pp. 245-254.

Laurence, D.C. (2002) Optimising mine closure outcomes for the community - lessons learnt, Minerals and Energy - Raw Materials Report, Vol. 17, pp. 27-38.

Lottermoser, B.G. (2007) Mine Wastes: characterization, treatment, environmental impacts, 2nd ed, Springer, New York, USA, $300 \mathrm{p}$.

MCA (2005) Enduring Value: Australian Minerals Industry Framework for Sustainable Development, by Minerals Council of Australia, Canberra, Australia, $24 \mathrm{p}$.

McCullough, C.D. and Van Etten, E.J.B. (2011) Ecological restoration of novel lake districts: new approaches for new landscapes, Mine Water and the Environment, Vol. 30, pp. 312-319.

Navarro, M., Pérez-Sirvent, C., Martínez-Sánchez, M., Vidal, J., Tovar, P. and Bech, J. (2008) Abandoned mine sites as a source of contamination by heavy metals: A case study in a semi-arid zone, Journal of Geochemical Exploration, Vol. 96, pp. 183-193.

Rio Tinto (2009) Closure Standard, Rio Tinto London, UK, 11 p.

Roldan, C.F. and Purvance, D. (2011) San Martin Mine in Honduras - from closure to sustainability, in Proceedings Sixth International Conference on Mine Closure (Mine Closure 2011), A.B. Fourie, M. Tibbett and A. Beersing (eds), 19-21 September 2011, Lake Louise, Canada, Australian Centre for Geomechanics, Perth, Vol. 2, pp. 461-470.

Sklenička, P. and Kašparová, I. (2008) Restoration of visual values in a post-mining landscape, Journal of Landscape Studies, Vol. 1, pp. 1-10.

Wälde, T. (1992) Environmental policies towards mining in developing countries, Journal of Energy and Natural Resources Law, Vol. 10, pp. 327-351.

World Bank (2010) Towards sustainable decommissioning and closure of oil fields and mines: A toolkit to assist government agencies, W.B.M. Initiative, Washington, DC, The World Bank. 
Closure planning in a developing country - a case study from the Phu Kham Mine,

A.P. Mauric et al. Laos, Southeast Asia 